\title{
Naphazoline Nitrate Treat the Frey Effect of Microwave and Other Sonic Weapon's Damages in Human's Internal, Endogenous Organs
}

\author{
Robert Skopec* \\ Researcher-analyst, Slovakia \\ *Corresponding author: Robert Skopec, Researcher-analyst, Slovakia
}

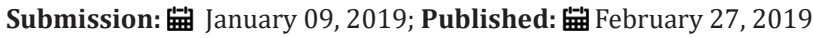

\begin{abstract}
State Department had evacuated a number of Americans from the U.S. consulate in Guangzhou, China after they experienced unexplained health issues. A group of U.S. diplomats stationed in China have been brought back to the states after being inflicted by a mystery illness that reportedly resembles the brain injuries previously suffered by staff in Cuba. At the end of the December 2018 we have found a medicine fully treating the damages caused the Frey Effect of Microvawe and other types of Sonic Weapons in Human's internal, endogenous organs. I am proposing to use Naphasoline nitrate, (former) nasal decongestatnt, to treat Carcinogenesis of the Human's internal, endogenous organs caused by Sonic Weapons through the release and cleaning of the Lymphatic ways in patients with colorectal, colon, pancreatic, breast, etc., cancer. I have proved this healing effect of the Naphazoline nitrate on Myself during treatment in last months of the year 2018.
\end{abstract}

Keywords: Nasal decongestatnt; Naphazoline nitrate; The Frey effect; The acoustic effect of microwaves; The sonic delusions; Bio-acoustic deterrents; Sonic weapons; Carcinogenesis; Loss of hearing; Balance; Brain injuries; Nausea; Headaches; Ear-ringing; Carcinogenesis of human's internal organs; Pancreatic cancer; Colon cancer; Colorectal cancer

\section{Introduction}

The New York Times reported that at least two employees removed from China experienced unusual noises while there. The Times reported that U.S. officials are suspicious that China or Russia may be involved. Secretary of State Mike Pompeo said the precise nature of the injuries suffered has not been determined and promised a "multi-agency response to the unexplained health incidents." Pompeo told the House Foreign Affairs Committee last month that the symptoms being reported in China were "entirely consistent with the medical indications that have taken place to Americans working in Cuba." Last October, the State Department ordered non-essential embassy personnel and the families of all staff to leave Havana, arguing the U.S. could not protect them from unexplained illnesses that have harmed at least 24 Americans. Symptoms, sounds and sensations reportedly varied dramatically from person to person. Some have permanent hearing loss or concussions, while others suffered nausea, headaches and earringing. Some were struggling with concentration or common word recall; the Associated Press has reported [1].

\section{Materials and Methods}

Exposure to microwave, infrasound, etc., sonic weapons has been demonstrated to affects recipients with symptoms including fear, sorrow, depression, anxiety, nausea, chest pressure and hallucination. It can cause objects to move through vibration and the body's internal organs can be affected. The term infrasonic applied to sound refers to sound waves below the frequencies of audible sound. Nominally includes frequencies under $20 \mathrm{~Hz}$. Sources of infrasound in nature includes volcanoes, avalanches, earthquakes and meteorites.

The healthy human ear can hear frequencies ranging from $20 \mathrm{~Hz}$ to $20,000 \mathrm{~Hz}$. Over time, the hair-like stereocilia may get damaged or broken. If enough of them are damaged, hearing loss results. The high frequency area of the cochlea is often damaged by loud sound. Infrasound is sound which extends below the range of human hearing (from $20 \mathrm{~Hz}$ to $0.001 \mathrm{~Hz}$ ), and it imitates from many natural and man-made sources. For example, some animals, such as whales, elephants and giraffes communicate using infrasound over long distances. Sonic and ultrasonic weapons (USW) are weapons of various types that use sound to injure, incapacitate, or kill a target. New personal communications show that infrasound can cause trough vibrations, resonance frequency about $7 \mathrm{~Hz}$ with internal organs of humans cause also cancer, such as colorectal cancer, colon cancer, pancreatic cancer, etc. [2-4]. Some of these weapons have been described as sonic bullets, sonic grenades, sonic mines, or sonic cannons. Some USWs make a focused beam of sound or ultrasound, some made an area field of sound. 
As an example of used sonic weapon we can use The LRAD Sound Cannon as an acoustic weapon and communication device. Developed by the LRAD Corporation to broadcast messages and pain-inducing deterrent tones over long distances. LRAD devices come in various iterations that produce varying degrees of sound. They can be mounted to a vehicle or handheld. Protests in Fergusson, Missouri have reached a terrifying fever pitch, and the ludicrously armed Fergusson Police Department is bringing all its crowd-control weapons to bear, tear gas, stun grenades, rubber bullets. One of the most controversial of those is the LRAD Sound Cannon. The device produces a sound that can be directed in a beam up to 30-degress wide, and the military-grade LRAD 2000X can transmit voice commands at up to $162 \mathrm{~dB}$ up to 5.5 miles away.

The LRAD Corporation says that anyone within a 100meters of the device's sound path will experience an extreme pain. The version generally utilized by Police Departments (the LRAD 500X) is designed to communicate at up to 2000meters during ideal conditions. In a typical outdoor environment, the device can be heard for 650 meters. The $500 \mathrm{X}$ version is also capable of short bursts of directed sound that cause headaches in anyone within a 300 meter range. Anyone within 15 meters of the device's audio path can experience permanent hearing loss. LRAD claims the device is not a weapon, but a directed-sound communication device.

The U.S. State Department has introduced a gaggle of diplomat's house from Guangzhou, China, over worry they had been affected by a mysterious illness that resembles a mind harm and has already affected U.S. group of workers in Cuba, a spokeswoman mentioned. After confirming one executive worker had "suffered a medical incident" in the southern Chinese town, the dept deployed a staff to display screen staff and members of the family at its consulate there, spokeswoman Heather Nauert mentioned in a remark on Wednesday. "As a result of the screening process so far, the department has sent a number of individuals for further evaluation and a comprehensive assessment of their symptoms and findings in the United States," Nauert mentioned [2]. Secretary of State Mike Pompeo launched a remark pronouncing the dept established a role power closing month 2018 "to direct a multi-agency response to the unexplained health incidents". "The precise nature of the injuries suffered by the affected personnel, and whether a common cause exists for all cases, has not yet been established," Pompeo mentioned.

\section{Developing a New Class of Weapons}

Allan H. Frey, has lived at his home outside Washington. In 1960, he stumbled on an acoustic effect of microwaves that was eventually named after him. Microwaves are ubiquitous in modern life. The short radio waves power radars, cook foods, relay messages and link cellphones to antenna towers. They're a form of electromagnetic radiation on the same spectrum as light and X-rays, only at the opposite end.

While radio broadcasting can employ waves a mile or more in length, microwaves range in size from roughly a foot to a tiny fraction of an inch. They're seen as harmless in such everyday uses as microwaving foods. But their diminutive size also enables tight focusing, as when dish antennas turn disorganized rays into concentrated beams. The dimensions of the human head, scientists say, make it a fairly good antenna for picking up microwave signals. Mr. Frey, a biologist, said he stumbled on the acoustic effect in 1960 while working for General Electric's Advanced Electronics Center at Cornell University. A man who measured radar signals at a nearby G.E. facility came up to him at a meeting and confided that he could hear the beam's pulses-zip, zip, zip. Intrigued, Mr. Frey traveled to the man's workplace in Syracuse and positioned himself in a radar beam. "Lo," he recalled, "I could hear it, too."

Mr. Frey's resulting papers-reporting that even deaf people could hear the false sounds-founded a new field of study on radiation's neural impacts. Mr. Frey's first paper, in 1961, reported that power densities 160 times lower than "the standard maximum safe level for continuous exposure" could induce the sonic delusions. His second paper, in 1962, pinpointed the brain's receptor site as the temporal lobes, which extend beneath the temples. Each lobe bears a small region-the auditory cortex-that processes nerve signals from the outer and inner ears. Investigators raced to confirm and extend Mr. Frey's findings. At first, they named the phenomenon after him, but eventually called it the microwave auditory effect and, in time, more generally, radio-frequency hearing.

The Soviets took notice. Not long after his initial discoveries, Mr. Frey said, he was invited by the Soviet Academy of Sciences to visit and lecture. Toward the end, in a surprise, he was taken outside Moscow to a military base surrounded by armed guards and barbedwire fences. "They had me visiting the various labs and discussing the problems," including the neural impacts of microwaves, Mr. Frey recalled. "I got an inside look at their classified program. "Moscow was so intrigued by the prospect of mind control that it adopted a special terminology for the overall class of envisioned arms, calling them psychophysical and psychotronic.

The Navy sought to paralyze. The Frey effect was to induce sounds powerful enough to cause painful discomfort and, if needed, leave targets unable to move. The weapon, the Navy noted, would have a "low probability of fatalities or permanent injuries." In a twist, the 2003 contract was awarded to microwave experts who had emigrated to the United States from Russia and Ukraine. It is unknown if Washington deploys such arms. But the Pentagon built a related weapon known as the Active Denial System, hailing it in a video. It fires an invisible beam meant to deter mobs and attackers with fiery sensations. Russia, China and many European states are seen as having the know-how to make basic microwave weapons that can debilitate, sow noise or even kill. Advanced powers, experts say, might accomplish more nuanced aims such as beaming spoken words into people's heads. Only intelligence agencies know which nations actually possess and use such unfamiliar arms. The basic weapon might look like a satellite dish. In theory, such a device might be hand-held or mounted in a van, car, boat or helicopter. Microwave arms are seen as typically working over relatively short distance-across the length of a few rooms or blocks. High-powered ones might be able to fire beams across several football fields, or even for several miles. 
Vladimir Putin, as Russia's president and prime minister, sought to recover the economic, political and strategic clout that the Soviets had lost. In December 2000, months after the start of his first presidential term, Mr. Putin flew to the island nation. It was the first visit by a Soviet or Russian leader since the Cold War. He also sought to resurrect Soviet work on psychoactive arms. In 2012, he declared that Russia would pursue "new instruments for achieving political and strategic goals," including psychophysical weapons.

\section{Discussion}

The LRAD device has been used on several occasions against activists in the USA. The first documented use was in Pittsburgh during the G20 Summit in 2009. The LRAD infra-sound device has potentially long-term effects, including permanent hearing loss and carcinogenesis [4]. Human discomfort starts when sound hits $120 \mathrm{~dB}$, well below the LRAD's threshold. Permanent hearing loss begins at $130 \mathrm{~dB}$, and if the device is turned up to $140 \mathrm{~dB}$, anyone within its path would not only suffer hearing loss, but also lose their balance, and be unable to move out of the path of the audio $[3,4]$.

LRAD systems are deployed at airports to sonically deter birds from residing in the pats of aircrafts. The bio-acoustic deterrent helps minimize bird strikes. It means that this device is available for military, police, secret services and also for agricultural companies to sonically deter birds, (in Slovakia reportedly suspected: Rudolf E. with AT Dunaj Dubnik, Slovakia, and his supporters Tomáš P. with Sebastian P. Their cars: NZ 123 ER, NZ 810 GK, TN 181 EB, NZ 708 FY, NZ 702 EG), etc. From the above information it follows that the similar bio-acoustic deterrents may have been developed also in other countries, first of all in other powers, such as Russia, China, India. Reportedly, above mentioned bio-acoustic deterrents may use also the Russian-based organized crime (RBOC), and also in different local groups of organized crime in V 4 countries.

As it was published in Western media, Russian ambassadors keep dying in mysterious ways. For example, former Russian ambassador to the United Nations, Vitaly Churkin, who died in February 2017 in New York. The US State Department asked the New York medical examiner's office to not release his autopsy. Reportedly, seven Russian ambassadors have died in mysterious ways over the last two years. What's concerning here is that Russia, according to Richard Walton, Scotland Yard's former counter-terror commander, is skilled it is disguising, probably by using biological (including bio-acoustic deterrents) or chemical agents that leave no trace. There are simply a lot of really weird coincidences in our world, Rolf Mowatt-Larsen, an intelligence expert at the Harvard Kennedy School, told to media.

From the official U. S. State Department data is known that already in the year 1978 from the 22 American diplomats working in Moscow had got 18 (!) health problems with their carcinogenesis. This situation has been only worsened further during later decades' development at the field of sonic weapons. Today there are a lot of possibilities for example to use sonic weapons from the space satellites, like is category of Russian ERA-GLONASS satellites, (they can blockade completely the whole electronic system of the terrestrial cars), etc. [5]. I was working at the Embassy of the Slovak Republic to Russia in Moscow during the years 2002-2006 as the First Secretary and have also some similar problems with Sonic Attacks. In December 2017 I have sent my request to the Miroslav Lajčák's Ministry of Foreign Affairs of the Slovak Republic (MoFA SR) in Bratislava to make investigation of my case of sonic health problems. The official Human Resources' General Secretary of the MoFA SR Pavol S. have sent me several months ago a letter rejecting my request for as minimum financial rehabilitation from suffered damage during my above diplomatic mission in abroad. It can be also understood probably as a shameful case of Moral Incompetence.

I hope that the investigation of the Havana-Case in U. S. State Department will prove my experiences. Especially, the AMA's (The America Medical Association) journal JAMA is by my opinion not the best solution for a new types of Sonic Weapons mechanisms investigation. I am also publishing articles in U. S. scientific journals at the field of Biology during several years and I am convinced that the JAMA is too conservative, old-fashioned, outdated scientific journal. They have only very limited information about new weapon technologies used recently by military and security forces of the modern states. From this reason I am rejecting the JAMA's conclusions in Havana-Case investigation as not qualified !

We have asked the Permanent Mission of Sweden to the United Nations to introduce a new initiative on illegalization of the Sonic Weapons (Bio-acoustic deterrents) with formulation of a new International Treaty on Prohibition of the use of the Sonic Weapons. They must be prohibited because are causing Carcinogenesis and Death of Humans. We here in my home in Dubnik, Slovakia have a new tragic case when one of the neighbors living next-door Tomas P. and Sebastian P. can be suspected if they were misused the Bioacoustic deterrents? Mária Deáková (66) who had in 3 weeks got a carcinogenesis of liver and from this reason has at July 17, 2018 died!

The Traditional Medicine has not enough information and means to heal these new types of health disorders caused by Sonic Weapons. We also propose to update the International Diseases' Register of the WHO with new Diagnosis of Carcinogenesis caused by Sonic Weapons. I am convinced now that the use of Sonic Weapons will bring a fundamental change in Diplomacy and in the means of International Policy making. But in a scientific paper that same month, James C. Lin of the University of Illinois, a leading investigator of the Frey effect, described the diplomatic ills as plausibly arising from microwave beams. Dr. Lin is the editor-inchief of Bio Electro Magnetics, a peer-reviewed journal that explores the effects of radio waves and electromagnetic fields on living things. In his paper, he said high-intensity beams of microwaves could have caused the diplomats to experience not just loud noises but nausea, headaches and vertigo, as well as possible brain-tissue injury. The beams, he added, could be fired covertly, hitting "only the intended target. "In February, ProPublica in a lengthy investigation mentioned that federal investigators were weighing the microwave theory. Separately, it told of an intriguing find. The wife of a member 
of the embassy staff, it reported, had looked outside her home after hearing the disturbing sounds and seen a van speeding away. A dish antenna could fit easily into a small van.

To date, the most detailed medical case for microwave strikes has been made by Beatrice A. Golomb, a medical doctor and professor of medicine at the University of California, San Diego. In a forthcoming paper to be published in October in Neural Computation, a peer-reviewed journal of the MIT Press, she lays out potential medical evidence for Cuban microwave strikes. She compared the symptoms of the diplomats in Cuba to those reported for individuals said to be suffering from radio-frequency sickness. The health responses of the two groups, Dr. Golomb wrote, "conform closely."

\section{Result}

Nasal decongestant naphasoline nitrate treat the Frey effect of microwave and other sonic weapons in human's internal, endogenous organs. The use of naphazoline nitrate may result in an analgesic effect upon first use, through activation of adrenergic and opioidergic systems, followed by a pro-migraine effect via a late induction of an inflammatory cascade, modulated by nitric oxide and arachidonic acid. The observation that naphazoline detoxification relieved the patient's headache, indicates that prolonged use of naphazoline may cause chronic headaches. Therefore, physicians should ask for details on the use of nasal decongestants in patients complaining of chronic headache, as they could potentially be suffering from a headache caused be the Frey effect of Sonic Weapons use against him.

The headache experienced by the patient was bilateral, throbbing, sometimes very severe, and associated with nausea, vomiting, photophobia, osmophobia and worsened by head movements. The patient had been treated by his general practitioner (GP) with medication to relieve the headache (metamizole, rizatriptan, zolmitriptan, acetylsalicylic acid, nimesulide, ibuprofen, naproxen sodium), consumed more than once a day, until the age of 24. Since then, he had stopped the consumption of such painkillers because he found that naphazoline nitrate nasal spray was more effective. He began with 2 shots $(0,14 \mathrm{mg}$ of drug for any shot) for each nostril 3 times a day, and at the time of presentation, due to pain recurrence, was using the spray 5-6 times a day, and experiencing immediate, yet temporary, relief of the symptoms every time. When asked, the patient said that he had used naphazoline nitrate nasal spray on an occasional basis since the age of 16 , in order to selfmedicate for self-diagnosed chronic rhinitis.

The chronic headache of the Frey effect disappeared following the treatment suggested by otolaryngologist. After three months of headache diary recording and clinical re-evaluation, the clinical picture was dramatically changed: patient presented only sporadic attacks of migraine without aura (ICHD-II 1.1). By an anamnesis reevaluation it emerged that an episodic headache arose in childhood and worsen over the years, until it became chronic by the age of 18. One year after naphazoline detoxification, the patient has suffered from a few attacks during the year, treated with triptans. Naphazoline is a sympathomimetic drug, an imidazolinic derivate with marked alpha-adrenergic activity. It enhances the release of noradrenaline from adrenergic termination, immediately relieving the nasal congestion thanks to its vasoconstricting action on the vessels of nasal mucosa. Because of its adrenergic activity, this drug can also produce adverse effects, like rhinitis medicamentosa, hypertension, headache and acute depression of central nervous system with marked sedation. Moreover, cases of ischemic and hemorrhagic stroke secondary to naphazoline have also been reported, mediated by the alpha1 and alpha2 adrenergic vasoconstrictive effect that is also exerted on brain vessels $[6,7]$.

Naphazoline can trigger headaches because of its adrenergic activity (Figure 1). Alpha1 receptors are associated with G-proteins that generate a cascade of events leading to the production of arachidonic acid (AA) and nitric oxide (NO). AA and NO release leads to a late inflammatory vasodilatation 8, 9 that could induce a migraine attack 10. Moreover, it is also possible that the same naphazoline nitrate, consumed by our patient, could have contributed to the production and release of further NO by a chemical reduction of the naphazoline salt. In fact, NO donors are currently used to induce migraine attacks in clinical and experimental settings 11 .

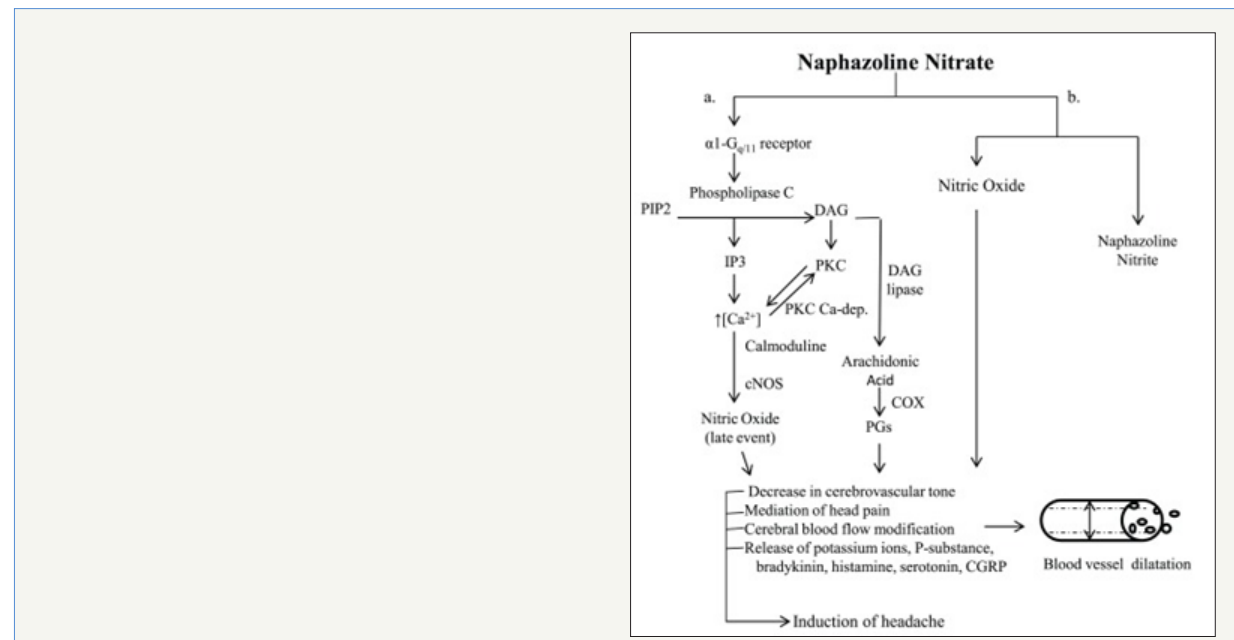

Figure 1: Events induced by naphazoline caused by the Frey effect's headache. 


\section{Events induced by naphazoline caused by the Frey effect's headache}

Naphazoline activates $\alpha 1$ receptors that are associated with G-proteins that cause the activation of phospholipase C. Phospholipase $\mathrm{C}$ cleaves phosphatidyl-inositol 4,5-bisphosphate (PIP2) into two second messengers, inositol 1,4,5-trisphosphate (IP3) and diacylglycerol (DAG) which in turn cause an increase in the level of calcium and protein kinase C. Diacylglycerol, by DAG lipase, takes part in the creation of arachidonic acid which is a precursor in the production of prostaglandins (PGs), mediated by cyclooxygenase (COX). The higher concentration of intracellular calcium allows an increase in the complex of calcium-calmodulin and therefore the activation of constitutive nitrous oxide synthetase (cNOS) with the generation of nitric oxide $[8,9]$.

Naphazoline nitrate can contribute to the production and release of further NO by a chemical reduction of the naphazoline salt. Prostaglandins and nitric oxide contribute to the activation of nociceptors and the transmission of the pain pulse from the periphery to the centre 10 . Consequently, there is a release of substances such as potassium ions, P-substance, bradykinin, histamine, serotonin and CGRP that keep nociceptors active and result in vasodilatation and extravasation of plasma proteins from the vessels [7-12].

However, despite the late effect as a migraine trigger factor, naphazoline might also have an early action as an anti-migraine agent acting on alpha receptors of muscle, immune cells, Locus Coeruleus and spinal cord (Figure 2). In fact, alpha2 adrenergic receptors have a peripheral analgesic effect, thanks to the activation of opioidergic receptors, via endogenous opioid release [12]. Moreover, both alpha1 and alpha2 adrenergic receptors agonists have been proposed to be specifically useful for the treatment of migraine by mechanisms that mediate the early vasoconstrictive effect related to their activation 8, similarly to triptans that carry out an analgesic action through the serotoninergic agonism that also mediates vasoconstriction.

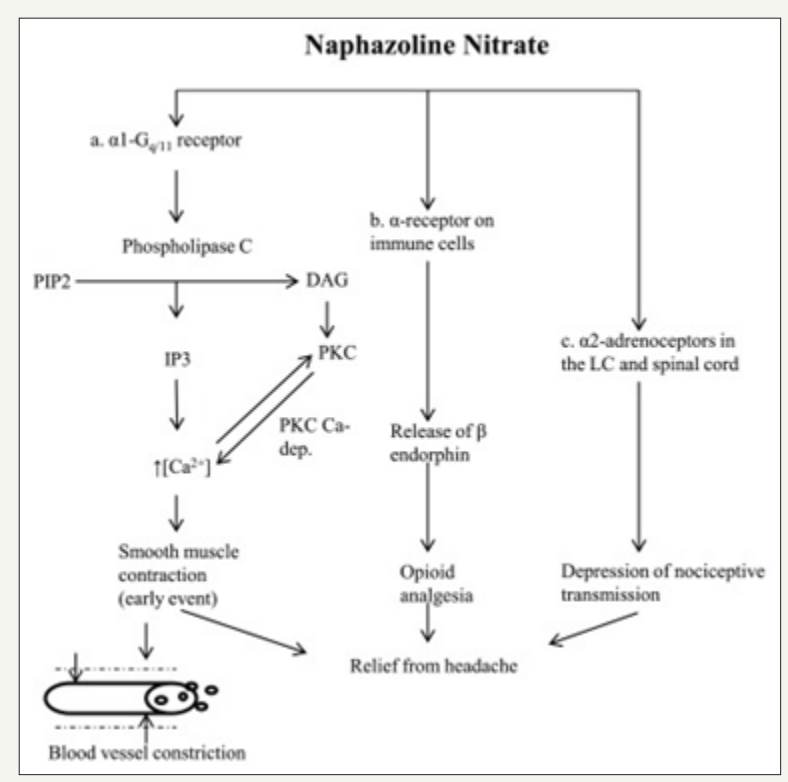

Figure 2: Possible early events that induce peripheral analgesic effect.

\section{Possible early events that induce peripheral analgesic effect}

Naphazoline activates alpha1 receptors that are associated with G-proteins that cause the activation of phospholipase C. Phospholipase C cleaves phosphatidyl-inositol 4,5-bisphosphate (PIP2) into inositol 1,4,5-trisphosphate (IP3). Consequently, there is a smooth muscle contraction due to an increase of intracellular calcium. Alpha-Receptors on immune cells release $\beta$-endorphins that cause opioid analgesia. c. Activation of alpha2 adrenoceptors in the Locus Coeruleus and spinal cord provokes the depression of nociceptive transmission [12].

We could therefore presume that in our patient, in a similar manner to the "triptans effect", naphazoline could exert an antimigraine action but also induce a rebound chronic headache due to medication overuse and/or a proinflammatory cytokinemediated headache induction. Indeed, our patient had experienced such a sudden analgesic effect; otherwise he would not have continued to take naphazoline.

\section{Conclusion}

I am proposing to use Naphasoline nitrate, (former) nasal decongestatnt, to treat Carcinogenesis of the Human's internal, endogenous organs caused by Sonic Weapons through the release and cleaning of the Lymphatic ways in patients with colorectal, colon, pancreatic, breast, etc., cancer. I have proved this healing effect of the Naphazoline nitrate on Myself during treatment in last months of the year 2018. 


\section{References}

1. Myers (2018) More Americans evacuated from chins over mysterious ailments. Dwkcommentaries, NY Times, USA.

2. (2018) US diplomats medical problems in Cuba, Dwkcommentaries, NY Times, USA.

3. Skopec R (2018) Darwinian selection transforms organisms to biorobots. World Journal of Biology and Medical, pp. 1-13.

4. Skopec R (2018) Science has a solution for sonic weapons caused cancer Research Trends in Hematology and Oncology: RTHO-101.

5. ERA GLONASS is the modern Russian system of emergency response similar to the European standard eCall/E112. Emergency response system. Revolvy, USA.

6. DeMarche E (2018) US brings home group of diplomats from China after mysterious illness: report. Fox Nation, USA.

7. Nappi G, Perrotta A, Rossi P (2008) Chronic daily headache. Expert Rev Neurother 8(3): 361-384.
8. Olesen J (2002) International classification of disorders, committee of the international headache society. Classification and diagnosis criteria for headache disorders, cranial neuralgia and facial pain. Cephalalgia 24(Suppl 1): 1-150.

9. Johnson DA, Hricik JG (1993) The pharmacology of alpha-adrenergic decongestants. Pharmacotherapy 13(6Pt2): 110S-115S.

10. Willems EW, Valdivia LF, Villalón CM, Saxena PR (2003) Possible role of alpha adrenoceptor subtypes in acute migraine therapy. Chephalalgia 23(4): 245-257.

11. Munaron L (2011) Shuffling the cards in signal transduction: Calcium, arachidonic acid and mechanosensitivity. World J Biol Chem 2(4): 59-66.

12. Romero TR, de Castro Perez A, de Francischi JN, Gama Duarte ID (2009) Probable involvement of alpha(2C) adrenoceptor subtype and endogenous opioid peptides in the peripheral antinociceptive effect induced by xylazine. Eur J Pharmacol 608(1-3): 23-7.

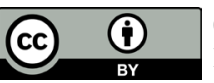

Creative Commons Attribution 4.0 International License

For possible submissions Click Here

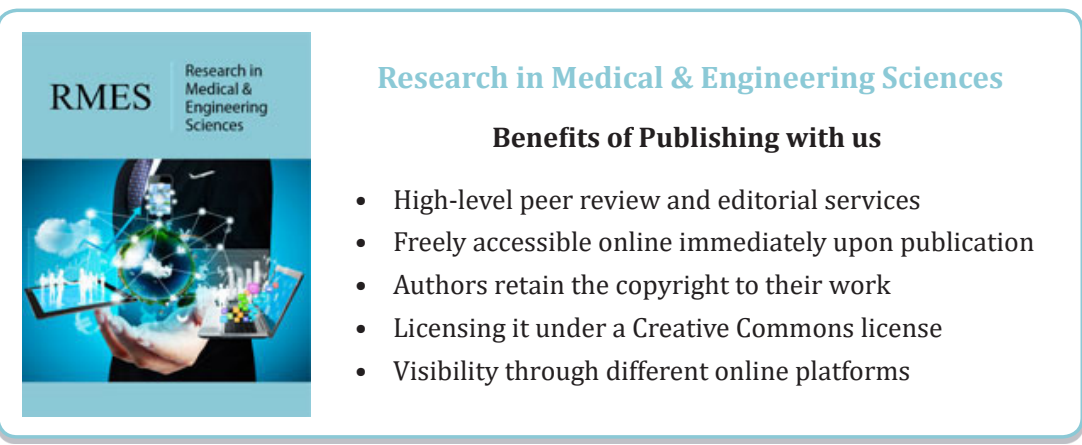

